\title{
Análise da relação com o saber dos professores em formação inicial - retomada dos estudos por parte de alunos já formados. Um estudo exploratório na Bélgica francófona
}

\section{Analysis of teachers' relationship with knowledge when in first teacher education - resumption of studies by students who have already graduated. An exploratory study in French-speaking Belgium}

https://doi.org/10.34112/2317-0972a2021V39n82p161-182

\section{DorothéE BAILLET ${ }^{1}$}

AmÉlie AdAM ${ }^{2}$

Guillaume De Bock ${ }^{3}$

RESUMO: O objetivo deste artigo é examinar a evolução da relação com o saber de professores em formação inicial e a retomada dos estudos universitários por parte de alunos já formados. Por meio de um questionário on-line, entrevistamos cerca de 100 alunos sobre a identidade e as dimensões epistêmicas de seus estudos. Os resultados tendem a mostrar que a dimensão identitária dos estudos evolui de uma relação mais instrumental para uma relação mais epistêmica ao longo do curso de ensino superior e que o significado atribuído ao termo "saber" seria antes influenciado pelo encontro com professores-pesquisadores. PALAVRAS-CHAVE: Relação com o saber; formação inicial de professores; retomada dos estudos de adultos.

ABSTRACT: In this article, we analyse the evolution of the relationship to knowledge of pre-service teachers and returning to university studies. Based on an online questionnaire, we interviewed a hundred students about the identity and epistemic dimensions of their studies. The results tend to show that the identity dimension of studies evolves from a more instrumental relationship to a more epistemic one over the course of higher education

1. Université Libre de Bruxelles, Bélgica.

2. Université Libre de Bruxelles, Bélgica.

3. Université Libre de Bruxelles, Bélgica. 
Análise da relação com o saber dos professores em formação inicial - retomada dos...

and that the meaning given to the term "knowledge" would rather be influenced by the encounter with teacher-researchers.

KEYWORDS: Report to knowledge; pre-service teacher education; adults returning to university.

\section{INTRODUÇÃO E CONTEXTUALIZAÇÃO}

Inicialmente estudada em populações de alunos do ensino fundamental e médio em áreas da classe trabalhadora (CHARLOT; BAUTIER; ROCHEX, 1992; CHARLOT, 1999), a relação com o saber e o aprender se espalhou gradualmente para outras populações e outros contextos de formação (THERRIAULT; BAILLET; CARNUS; VINCENT, 2017a; BERNARD et al., 2014). De fato, podemos constatar a existência de pesquisas dedicadas à análise da relação com o saber de estudantes universitários (por exemplo: BAILLET, 2020; CHARLOT; NEVES; SILVA, 2017; PAIVANDI, 2015), mas também de docentes em formação (por exemplo: CARNUS; BAILLET; THERRIAULT; VINCENT, 2019; THERRIAULT; BAILLET; CARNUS; VINCENT, 2017a, b). Esta pesquisa se encaixa nesse duplo contexto. De fato, interessa-nos a relação com o saber e o aprender dos alunos matriculados no ensino superior em formação inicial de professores e dos alunos já titulares do diploma de professor que regressam aos estudos universitários. Em outras palavras, estamos interessados em ambos os alunos - alunos no início da formação ou na continuação de seus estudos - que, em algum momento de suas carreiras, estarão exercendo a profissão docente. Antes de apresentar o quadro de referência e a problemática da nossa investigação, parece imprescindível apresentar os elementos que atualmente caracterizam a estrutura da formação inicial de professores.

Ao contrário do que se observa em outros países, a formação inicial de professores difere de acordo com a idade dos alunos que ensinarão. Professores que pretendem exercer a sua profissão na educação pré-escolar (dos 3 anos aos 6 anos), no ensino básico (dos 6 aos 12 anos) e no denominado ensino secundário "inferior" (dos 12 aos 15 anos) são obrigados a realizar estudos profissionais superiores em três anos ("bacharelado"). Estes cursos de formação são organizados em instituições de ensino superior denominados "Hautes Écoles" e conduzem automaticamente à obtenção de uma qualificação docente. Os primeiros (professores pré-escolares e primários) recebem uma formação pedagógica e didática 
transdisciplinar adaptada ao trabalho com a idade de seus futuros alunos, enquanto os segundos (professores do ensino médio) são formados em questões pedagógicas e didáticas de grupos disciplinares específicos (por exemplo: francês / francês como língua estrangeira / biologia / química / física, geografia / história / ciências sociais etc.). Em outras palavras, se os primeiros podem ser considerados professores generalistas, os segundos devem ser vistos como especialistas nas disciplinas que ensinam. No final do curso, os professores do ensino secundário inferior obtêm um título educacional intitulado "Agrégation de l'Education Secondaire Inférieur" (AESI). Quanto aos professores que atuam no chamado ensino médio "superior" (15 a 18 anos), realizam estudos universitários de 5 anos em que está integrada uma formação pedagógica e didática ("mestrado / mestrado com finalidade didática"), ou estudos universitários de 5 anos ("mestrado / mestrado") que podem então ser concluídos por formação pedagógica e didática de um ano. Em ambos os casos, estes cursos conduzem à obtenção de um título educacional intitulado "Agrégation de l'éducation secondaire supérieure" (AESS). Em comparação com os seus colegas que trabalham no ensino secundário inferior, os professores titulares de um AESS têm, portanto, a particularidade de terem aprofundado o estudo de uma disciplina, compreendida em sua dimensão epistemológica (por exemplo: línguas românicas, ciências matemáticas, ciências biológicas etc.), e de terem se valido de uma formação pedagógica e didática menos aprofundada. Em outras palavras, ao aprofundar a análise, podemos considerar que a relação entre "pedagogia" e "didática e conhecimento disciplinar" se inverte, dependendo do nível de escolaridade.

Após a obtenção do diploma que permite a docência, os alunos podem prosseguir a sua formação com o grau de mestre em ciências da educação ( 2 anos), que visa aprofundar um conjunto de questões fundamentais da educação, incluindo a investigação. Para os alunos concluintes da Haute École, o acesso a este mestrado está condicionado à conclusão com aproveitamento de um programa de curso denominado "programa complementar", cuja duração equivale a um ano de formação.

Nesta investigação, interessa-nos mais particularmente a relação com o saber de três grupos de alunos: os inscritos (1) no primeiro ano na formação inicial de docência na Haute École, (2) no curso complementar no grau de mestre em ciências da educação e (3) pretendentes ao grau de mestre em ciências da educação. 
Análise da relação com o saber dos professores em formação inicial - retomada dos...

\section{ESTRUTURA DE REFERÊNCIA E PROBLEMÁticA}

Em nosso trabalho, a noção de relação com o saber é conceituada com base no trabalho do grupo ESCOL (CHARLOT et al., 1992; CHARLOT, 1997, 1999; BAUTIER ; ROCHEX, 1998) e em um conjunto de trabalhos que são parte da abordagem sociológica da relação com o saber (JELLAB, 2011; BEAUCHER, 2004; BEAUCHER et al., 2013). A relação com o saber é definida como uma relação com o aprender que se elabora e evolui ao longo das experiências de aprendizagens escolares e extra-escolares de um sujeito necessariamente complexo e singular (BAILLET; REY, 2015, 2020). Ela dá acesso ao sentido e ao valor que os sujeitos conferem a tudo o que se relaciona com o ato de aprender (BAUTIER; ROCHEX, 1998) e se constrói a partir da articulação de três registros: o registro epistêmico, o registro de identidade e o registro social (CHARLOT, 1997), que podem ser circunscritos respectivamente pelas seguintes questões: o que é aprender? Por que aprender? De onde venho e com quem aprendo? Se o registro epistêmico da relação com o saber se refere "à natureza da atividade que o sujeito coloca sob os termos aprender, saber: aprender é fazer o quê?” (BAUTIER; ROCHEX, 1998, p. 34), o registro de identidade diz respeito "ao modo como o conhecimento ganha sentido em relação aos modelos, expectativas, marcadores de identificação, da vida que queremos levar ao trabalho que você deseja realizar" (BAUTIER; ROCHEX, 1998, p. 34). Por fim, o cadastro social permite especificar não só a história social de um sujeito, mas também o lugar que outras pessoas nele ocupam (pais, amigos, professores etc.). Charlot (1997) alerta, no entanto, para um uso determinístico dessa dimensão: para ele, se a história social de um aluno influencia sua trajetória educacional por meio da posição que ocupa no espaço social, ela não o determina.

Se esta conceituação enfatiza o interesse de estudar a relação com o saber dos alunos, ou mais amplamente dos estudantes, para identificar lógicas potencialmente diferenciadoras em termos de trajetórias escolares, também permite sublinhar o principal interesse deste estudo, ou seja, a dimensão evolutiva da relação com o saber e, em particular, a influência das experiências de formação e do aprender na construção da relação dos sujeitos com o saber. Para alunos em início de bacharelado na Haute École, essa experiência é baseada principalmente em sua formação educacional anterior. Além desse curso, somam-se à formação inicial em docência para os alunos matriculados no programa complementar e para os alunos matriculados no mestrado em ciências da educação as várias experiências do aprender 
realizadas ao longo do programa complementar. Portanto, se considerarmos a relação com o saber dos alunos do primeiro ano da Haute École como um ponto de referência ou comparação, podemos esperar ver mudanças nessa relação para os outros dois grupos de alunos. No que diz respeito aos alunos inscritos no programa complementar, verifica-se a influência da formação orientada essencialmente para a profissionalização, em que os saberes ministrados dizem respeito tanto ao saber para ensinar como ao saber $a$ ensinar (LUSSI BORER, 2009; MOSCONI, 2020). Quanto aos alunos matriculados no mestrado em ciências da educação, foram, frequentemente, pela primeira vez, durante o curso complementar, confrontados com os professores-pesquisadores. Porém, para um pesquisador, podemos considerar que o conhecimento possui duas características principais: é uma construção humana necessariamente dependente de suas condições de produção e pode ser considerada o resultado de uma prática cujo objetivo principal é a produção de conhecimento científico. Além disso, ao contrário dos cursos organizados na Haute École, a universidade tem como característica a formação na e pela pesquisa. Em suma, e forçando um pouco a linha, podemos portanto considerar que se o objetivo principal da formação inicial docente é formar profissionais (e não pesquisadores), o mestrado em ciências da educação tem mais a finalidade de abrir os alunos para as práticas de pesquisa e seus desafios. Esses cursos ajudam a modelar, a modificar a relação com o saber dos alunos que neles se envolvem? Essa é a questão central para a qual tentaremos dar uma resposta neste texto.

\section{Metodologia}

Conforme indicado acima, o objetivo da pesquisa foi analisar a influência da carreira escolar e da formação na relação com o saber de três grupos distintos de alunos: (1) alunos do primeiro ano em formação inicial em docência na Haute École, (2) alunos matriculados no programa complementar ao mestrado em ciências da educação e (3) alunos matriculados no mestrado em ciências da educação.

\subsection{Questões de PESQUisa}

No que se refere ao quadro conceitual e à nossa problemática, circunscrevemos um conjunto de questões com o objetivo de orientar a construção de nosso instrumento de coleta de dados e sua análise. Como parte de um processo exploratório, 
Análise da relação com o saber dos professores em formação inicial - retomada dos...

essas questões são voluntariamente amplas e nos permitem entender melhor quem são os sujeitos que estudamos, mas também as razões pelas quais estão engajados nos estudos superiores e universitários, as dificuldades e mudanças que esperam viver lá ou o significado que dão aos termos "aprender" e "saber". Listamos essas questões a seguir e procuramos, por meio da análise das respostas a um questionário, verificar se é possível identificar variações entre esses três grupos de alunos.

Quem são os alunos matriculados na formação inicial em docência, no programa complementar e no mestrado em ciências da educação? De onde eles vêm? Por que eles realizaram esses estudos? O que eles esperam disso? Que significado(s) eles dão aos termos "saber" e "aprender"? Que mudanças e quais dificuldades eles preveem (ou encontraram) no início de sua formação?

\subsection{Coleta E ANÁlise DE DADOS}

Para responder às questões de pesquisa apresentadas, adaptamos para a nossa população um questionário impresso construído como parte de uma pesquisa sobre a relação com o saber dos alunos que ingressam na universidade (BAILLET, 2017). Esse questionário deveria ser inicialmente respondido por alunos presenciais. No entanto, de acordo com as diretivas do governo implementadas no contexto da crise da saúde, o acesso a instituições de formação era impossível. Primeiro, transpusemos o questionário impresso para o formato digital. Após duas semanas de distribuição do questionário on-line e seguindo o número muito limitado de respostas obtidas, tivemos que reorganizar - pela terceira vez - o questionário inicial. Das respostas ao questionário inicial de uma coorte de alunos matriculados em 2015-2016 no programa complementar ao mestrado em ciências da educação e a partir de algumas referências da literatura científica (DUBET, 1994, 1996; VERTONGEN et al., 2009; BAILLET, 2017), inicialmente transformamos as questões abertas em questões fechadas. Uma vez construídas as perguntas e itens, o questionário foi distribuído on-line por meio de redes sociais e contatos em estabelecimentos de formação durante um mês e meio.

O questionário é composto por cinco questões para as quais os sujeitos são convidados a escolher uma ou mais respostas de um conjunto de proposições (Q1a, Q1b, Q2, $\left.\mathrm{Q}_{3}\right)$, ou a produzir e classificar um conjunto limitado de respostas curtas $\left(\mathrm{Q}_{4}, \mathrm{Q}_{5}\right)$. A função da primeira pergunta é entender por que os alunos optaram por se engajar no ensino superior (Q1a) e o que esperam disso (Q1b). Com isso, é possível explorar o registro identitário da relação dos alunos com o saber e com o aprender. Para construir 
as proposições entre as quais os alunos poderiam fazer uma ou mais escolhas, contamos com os resultados dos trabalhos de Baillet (2017), Bautier e Rochex (1998), Paivandi (2015) e Vertongen et al. (2009). A segunda e terceira questões visam compreender o significado que os alunos atribuem aos termos "aprender" $\left(\mathrm{Q}_{2}\right)$ e "saber" $\left(\mathrm{Q}_{3}\right)$ e, portanto, correspondem à exploração do registro epistêmico da relação com o saber. As propostas disponíveis para os alunos vêm principalmente de Baillet (2017), que por sua vez se baseou nos trabalhos de Bautier e Rochex (1998) e Paivandi (2015) para categorizar as respostas dos alunos em sua pesquisa. As duas últimas questões enfocam as mudanças $\left(\mathrm{Q}_{4}\right)$ e as dificuldades $\left(\mathrm{Q}_{5}\right)$ que os alunos esperam no início de seus estudos (na Haute École ou na universidade) ou que enfrentaram durante sua carreira universitária. Finalmente, o questionário finaliza com um conjunto de questões que permitem conhecer a formação anterior dos alunos, mas também compreender a sua origem sociodemográfica. Embora insuficiente, esta parte do questionário permite, portanto, abordar o cadastro social da relação com o saber.

O questionário online coletou respostas de 102 alunos, dos quais 47 estão matriculados no bacharelado na Haute École (BA) e 54 no mestrado em ciências da educação (MA). Além destes dois primeiros grupos de alunos, um terceiro, composto por 50 alunos matriculados no programa complementar de mestrado em ciências da educação (CP) da Universidade Livre de Bruxelas, respondeu ao questionário inicial impresso em 2015-2016.

Os dados dos dois questionários foram processados e analisados de forma diferente. Para o questionário on-line, calculamos - para os dois grupos de alunos - a porcentagem de itens selecionados para questões fechadas ( $\left.\mathrm{Q}_{1} \mathrm{a}, \mathrm{Q}_{1} \mathrm{~b}, \mathrm{Q}_{2}, \mathrm{Q}_{3}\right)$. Quanto às respostas produzidas para as questões $4 \mathrm{e} 5$, foram codificadas a partir do trabalho de Baillet $(2017,2020)$ e, então, também foram objeto de cálculo percentual. Para cada questão, portanto, temos respostas dicotômicas: $\mathrm{o}$ aluno selecionou ou não selecionou / produziu um item / determinada resposta. Em segundo lugar, procuramos saber se as respostas dos alunos matriculados na Haute École e na universidade diferiam significativamente. Para fazer isso, realizamos testes estatísticos $\chi 2$. Para o questionário aberto, categorizamos as respostas dos alunos com base nos itens ou na categorização das respostas produzidas no questionário on-line. Ou seja, agimos "como se" os alunos matriculados no programa complementar ao mestrado em ciências da educação tivessem respondido ao questionário on-line. Essa manipulação permitiu calcular as percentagens de respostas deste grupo de alunos para cada uma das questões. No entanto, se os incluirmos nas tabelas a seguir, não podemos usá-los para testes estatísticos. $\mathrm{Na}$ 
Análise da relação com o saber dos professores em formação inicial - retomada dos...

verdade, sendo retiradas de um questionário aberto, essas respostas não podem ser comparadas como são com as respostas do questionário fechado distribuído on-line, o que constituiu, incontestavelmente, um limite importante para a pesquisa.

\subsection{DESCRIÇÃO DA POPULAÇÃO}

Antes de apresentar os resultados de nossas análises, parece interessante descrever rapidamente as características sociodemográficas dos três grupos de alunos que compõem a população da pesquisa (Tabela 1).

\begin{tabular}{|c|c|c|c|c|}
\hline & Variáveis & $\begin{array}{c}\text { BA } \\
(\mathrm{n}=47)\end{array}$ & $\begin{array}{c}\text { MA } \\
(\mathrm{n}=54)\end{array}$ & $\begin{array}{c}\text { PC } \\
(\mathrm{n}=50)\end{array}$ \\
\hline \multirow{3}{*}{ Idade } & Mín.-Máx. (Anos) & $18-58$ & $21-52$ & $20-35$ \\
\hline & Média & 25,79 anos & 27,67 anos & 23,53 anos \\
\hline & Desvio padrão & 8,95 & 6,9 & 3,28 \\
\hline \multirow{4}{*}{$\begin{array}{l}\text { Tipo de ensino } \\
\text { médio }\end{array}$} & Geral & $51,1 \%$ & $83,3 \%$ & $74,5 \%$ \\
\hline & Técnico de transição & $10,6 \%$ & $7,4 \%$ & $7,8 \%$ \\
\hline & Técnico de qualificação & $31,9 \%$ & $9,3 \%$ & $17,6 \%$ \\
\hline & Profissional & $6,4 \%$ & $1,9 \%$ & $0 \%$ \\
\hline \multirow{3}{*}{ Repetição } & Primário & $19,1 \%$ & $7,4 \%$ & $2,0 \%$ \\
\hline & Secundário & $53,2 \%$ & $35,2 \%$ & $35,3 \%$ \\
\hline & Bacharel & $57,4 \%$ & $24,1 \%$ & $I^{*}$ \\
\hline \multirow{7}{*}{$\begin{array}{l}\text { Diploma de } \\
\text { bacharel ** }\end{array}$} & Professor/a de pré-escola & $27,7 \%$ & $7,4 \%$ & $9,8 \%$ \\
\hline & Professor/a de escola primária & $19,1 \%$ & $51,9 \%$ & $58,2 \%$ \\
\hline & AESI & $44,7 \%$ & $25,9 \%$ & $15,7 \%$ \\
\hline & Assistente social & $0 \%$ & $3,7 \%$ & $0 \%$ \\
\hline & Educador/a especializado & $2,1 \%$ & $1,9 \%$ & $5,9 \%$ \\
\hline & Assistente de psicologia & $0 \%$ & $0 \%$ & $1,9 \%$ \\
\hline & Outro & $6,4 \%$ & $7 \%$ & $5,9 \%$ \\
\hline \multicolumn{5}{|c|}{ Tabela 1 - Descrição dos três grupos de alunos } \\
\hline \multicolumn{5}{|c|}{ * Pergunta inexistente no questionário aberto distribuído em 2015-2016. } \\
\hline \multicolumn{5}{|c|}{ ** Para alunos de bacharelado: os percentuais indicados correspondem às opções escolhidas pelos alunos. } \\
\hline \multicolumn{5}{|c|}{$\begin{array}{l}\text { Para os alunos do mestrado e do programa complementar, os percentuais indicados correspondem ao } \\
\text { grau de licenciado efetivamente adquirido. }\end{array}$} \\
\hline
\end{tabular}


A idade média de nossa população está entre 25,79 e 27,67 anos.

A maioria dos respondentes (51,1\% para titulares de bacharelado e $83,3 \%$ para mestres) concluiu o ensino médio no ensino médio geral. Em seguida, vêm os alunos que deram continuidade aos estudos em técnico de transição (10,6\% para bacharéis e $7,4 \%$ para mestres) e em técnico de qualificação (31,9\% para bacharéis e $9,3 \%$ para mestres). Há que se referir ainda a presença de alunos do ensino profissional (6,4\% para bacharéis e $1,9 \%$ para mestres).

Em relação à trajetória anterior, 19,1\% dos bacharéis e 7,4\% dos mestres indicam ter reprovado pelo menos uma vez no primário. Há que se referir, ainda, que o conjunto da coorte declara ter reiniciado pelo menos uma vez o ensino secundário (53,2\% para bacharéis e $35,2 \%$ para mestres). Além disso, mais da metade dos entrevistados na Haute École (57,4\%) indicam ter reprovado no bacharelado. Essa taxa sobe para $25,4 \%$ para alunos de mestrado.

A maioria dos alunos licenciados $(44,7 \%)$ visa obter um certificado de ingresso no ensino secundário inferior (AESI), seguido do ensino pré-escolar $(27,7 \%)$ e primário $(19,1 \%)$. Há que se referir ainda a presença de alguns alunos inscritos para o ensino de educador especializado $(2,1 \%)$ e de $6,4 \%$ de inquiridos inscritos em estágios que não correspondem a nenhuma das categorias mencionadas.

Entre os alunos matriculados no mestrado em educação, a maioria dos alunos possui diploma de professor do ensino fundamental $(51,9 \%)$ ou AESI $(25,4 \%)$. A quarta parte restante é composta por alunos titulares do diploma de professor da pré-escola $(7,4 \%)$, educador especializado $(3,7 \%)$, auxiliar de psicologia $(1,9 \%)$ ou outro curso de bacharelado (7\%).

\section{Resultados ${ }^{4}$}

\subsection{REgistro DE IDENTIDADE}

O registro de identidade é abordado a partir de duas questões. A primeira diz respeito aos motivos de ingresso na formação escolhida pelos alunos e a segunda às expectativas dos alunos em relação aos estudos que realizaram.

4. Recorde-se que as comparações dos resultados das análises estatísticas referem-se apenas aos alunos matriculados no bacharelado da Haute École e no mestrado em ciências da educação. Os resultados dos alunos matriculados no programa complementar são fornecidos apenas a título informativo. 
Análise da relação com o saber dos professores em formação inicial - retomada dos...

A Tabela 2 detalha os motivos de ingresso na formação para os três grupos de alunos entrevistados. Para os licenciados, estes são os motivos que os levaram a iniciar a sua formação inicial na Haute École. Os alunos de mestrado, por sua vez, visam aqui os motivos que os levaram a buscar o mestrado em ciências da educação após a formação inicial docente.

\begin{tabular}{llll}
\hline Você está agora no ensino médio / universida- & BA & MA & PC \\
de, você optou por se matricular lá para... & 34,0 & 85,2 & 60,8 \\
\hline melhorar meu conhecimento & 72,3 & 57,4 & 43,1 \\
\hline treinar para uma profissão (BA) ou reorientar (MA)* & 27,7 & 51,9 & 13,7 \\
\hline alcançar um novo aprendizado & 8,5 & 27,8 & 2.0 \\
\hline descobrir a vida na universidade/colégio & 17,0 & 9,3 & 9,8 \\
\hline descobrir uma nova maneira de aprender & 8,5 & 14,8 & 5,9 \\
\hline treinar em pesquisa & 12,8 & 13 & 3,9 \\
\hline conhecer outras pessoas, outras culturas, etc. & 4,3 & 35,2 & 5,9 \\
\hline escapar ou atrasar a entrada no comércio & & \\
\hline
\end{tabular}

Tabela 2 - Motivos de ingresso em estágio de alunos de bacharelado e mestrado (em porcentagem) * O texto era diferente dependendo do grupo-alvo.

Em primeiro lugar, podemos perceber que os dois grupos de alunos evocam motivos semelhantes para a escolha da formação. Com efeito, embora em proporções variáveis, os dois grupos veem na sua formação a possibilidade de uma (re)orientação profissional, uma nova forma de aprender, de aprofundar os seus conhecimentos ou de conhecer novas pessoas e outras culturas. Note-se que, se entre o conjunto dos motivos propostos aos respondentes do questionário fechado, o aprofundamento de conhecimentos é a razão mais escolhida pelos estudantes do mestrado em ciências da educação, esta é igualmente aquela que domina largamente os motivos espontaneamente evocados pelos estudantes inscritos no programa complementar em ciências da educação para justificar sua entrada na universidade

Estatisticamente e apesar das fortes variações observadas de um padrão para outro, apenas quatro padrões de entrada são significativamente diferentes. Na verdade, os alunos de mestrado estão mais focados em aprofundar seus conhecimentos $\left(\chi^{2}\right.$ $(1)=27,728, \mathrm{p}<0,001)$, em alcançar de uma nova aprendizagem $\left(\chi^{2}(1)=6.099, \mathrm{p}\right.$ 
<0.05), na descoberta da vida em sua nova instituição $\left(\chi_{2}(1)=6,108, \mathrm{p}<0,05\right)$ e na possibilidade de escapar ou atrasar a entrada na profissão $\left(\chi_{2}(1)=14,597, \mathrm{p}<0,001\right)$.

A Tabela 3 resume as expectativas dos alunos em relação aos estudos que realizaram. No geral, três expectativas principais predominam entre os alunos de mestrado. Trata-se de abrir portas no campo da educação, de desenvolver ou enriquecer a sua prática e de se beneficiar de um aumento salarial. No que diz respeito aos bacharéis, suas expectativas parecem mais dispersas. Observe-se, entretanto, que abrir portas na educação é a expectativa mais citada.

\begin{tabular}{lccc}
\hline $\begin{array}{l}\text { Você está agora no ensino médio / universida- } \\
\text { de, que você esperava? }\end{array}$ & BA & MA & PC \\
\hline para desenvolver / enriquecer minha prática & 42,6 & 64,8 & 27,5 \\
\hline me sinto mais legítimo na minha profissão & 25,5 & 25,9 & 2.0 \\
\hline continuo minha formação & 34,0 & 44,4 & 52,9 \\
\hline um aumento de salário & 17,0 & 63 & 2.0 \\
\hline Portas abertas para mim na educação & 85,1 & 72,2 & 17,6 \\
\hline Não tenho expectativas especiais & 4,3 & 0 & 5,3 \\
\hline
\end{tabular}

Tabela 3 - Expectativas relacionadas à formação de alunos de bacharelado e mestrado (em porcentagem)

A comparação dos dois grupos revela diferenças importantes para dois itens: 0 desejo de desenvolver e enriquecer a própria prática $\left(\chi_{2}(1)=5,021, p<0,05\right)$, bem como a expectativa de aumento salarial $\left(\chi_{2}(1)=21,834, p<0,001\right)$. Essas duas expectativas são mais mencionadas pelos alunos de mestrado em ciências da educação.

\subsection{Registro ePIStÊMico}

A exploração do registro epistêmico se assenta em duas questões: "para você, aprender é..." e "para você, saber é...”. Para ambas as perguntas, os alunos podem escolher uma ou mais afirmações entre as oferecidas.

A Tabela 4 mostra a porcentagem de alunos que selecionaram cada proposta. Podemos perceber que os alunos do primeiro ano da Haute École e do mestrado na universidade compartilham em grande parte a forma de definir o que é 
Análise da relação com o saber dos professores em formação inicial - retomada dos...

“aprender”. De fato, em ambos os grupos, aprender é sinônimo de desenvolvimento pessoal e intelectual, de desenvolvimento da cultura e da curiosidade, mas sobretudo de aquisição de novas competências.

\begin{tabular}{lccc}
\hline Na sua opinião, aprender é... & BA & MA & PC \\
\hline evoluir em um nível pessoal & 44,7 & 46,3 & 25,5 \\
\hline evoluir no nível relacional & 29,8 & 22,2 & 3,9 \\
\hline adquirir novas habilidades e know-how & 72,3 & 75,9 & 11,8 \\
\hline implementar habilidades / know-how. & 42,6 & 50 & 3,9 \\
\hline adquirir novos conhecimentos & 59,6 & 51,9 & 37,3 \\
\hline evoluir intelectualmente & 53,2 & 51,9 & 33,3 \\
\hline desenvolver sua cultura, descobrir e ser curioso & 55,3 & 53,7 & 13,7 \\
\hline
\end{tabular}

Tabela 4 - Conceito de aprender expresso por alunos de licenciatura e mestrado (em percentagem)

Se não foi detectada diferença significativa entre os dois grupos-alvo, notamos, no entanto, que os alunos licenciados mencionam mais a ligação entre "aprender" e adquirir conhecimento, mas também associam esse termo a uma evolução relacional. Os mestrandos, por sua vez, falam com mais frequência do uso de habilidades para definir o que é "aprender".

A Tabela 5 resume como os alunos definem o termo "conhecimento". Sobre esse assunto, uma primeira leitura das percentagens de cada item selecionado pelos alunos revela concepções bastante semelhantes. Uma minoria de alunos em cada grupo menciona o conhecimento como sendo um objeto intelectual, uma verdade ou mesmo uma opinião.

\begin{tabular}{lccc}
\hline Na sua opinião, o conhecimento é... & BA & MA & PC \\
\hline conhecimento & 36,2 & 46,3 & 45,1 \\
\hline transmissível & 53,2 & 38,9 & 9,8 \\
\hline a verdade & 6,4 & 3,7 & 0 \\
\hline uma opinião & 8,5 & 7,4 & 0 \\
\hline
\end{tabular}




\begin{tabular}{lccc}
\hline por experiência pessoal & 31,9 & 18,5 & 3,9 \\
\hline uma construção humana & 29,8 & 40,7 & 2.0 \\
\hline transferível & 36,2 & 29,6 & 2.0 \\
\hline utilizável & 34,0 & 18,5 & 13,7 \\
\hline uma vantagem & 29,8 & 13 & 11,8 \\
\hline o resultado de um aprendizado & 55,3 & 40,7 & 17,6 \\
\hline um objeto intelectual & 25,5 & 24,1 & 9,8 \\
\hline propenso a evoluir & 48,9 & 79,6 & 5,9 \\
\hline
\end{tabular}

Tabela 5 - Conceito de conhecimento expresso por alunos de licenciatura e mestrado (em percentagem)

Embora a priori relativamente semelhante, as análises estatísticas revelaram duas diferenças significativas. Na verdade, os alunos de bacharelado consideram o conhecimento mais como um ativo $\left(\chi_{2}(1)=4,319, \mathrm{p}<0,05\right)$, enquanto os que estão no mestrado dizem com mais frequência que o conhecimento tende a evoluir $\left(\chi_{2}^{2}\right.$ $(1)=10,454, p<0,001)$.

Sem ser apoiado por análises estatísticas, também existem outras diferenças de concepção. Assim, os alunos de mestrado descrevem com mais frequência o conhecimento como conhecimento e construção humanos. Além disso, os alunos do bacharelado indicam mais que o conhecimento é resultado da aprendizagem, que é utilizável, transmissível e transferível ou que vem da experiência pessoal.

\subsection{Registro social}

Dadas as diversas alterações no instrumento de coleta de dados, o registro social só pôde ser abordado por meio da percepção dos alunos sobre o nível sociodemográfico de sua família. Para isso, reproduzimos a metodologia proposta por Darnon et al. (2018), pedindo aos alunos que colocassem sua família em uma escala de 1 (desfavorecidos) a 10 (muito privilegiados). 
Análise da relação com o saber dos professores em formação inicial - retomada dos...

\begin{tabular}{lccc}
\hline & BA & MA & PC \\
\hline Média & 5.09 & 5,91 & /* $^{*}$ \\
Desvio padrão & 1.975 & 2.049 & /* $^{*}$ \\
\hline
\end{tabular}

Tabela 6 - Percepção do nível sociodemográfico da família

* Pergunta inexistente no questionário aberto distribuído em 2015-2016.

Para verificar se a percepção do nível sociodemográfico familiar difere entre os alunos de bacharelado e mestrado, foram realizados testes de comparação de médias para amostras independentes. Parece que os alunos de graduação se consideram significativamente parte de um ambiente sociodemográfico menos favorecido do que os alunos de mestrado $(t(97)=-2,012, p<0,05)$. Apesar dessa diferença significativa, no entanto, deve-se destacar que, de maneira geral, os alunos estão no centro da escala proposta.

\subsection{MUdANÇAS E DifiCULdAdES ESPERADAS OU OBSERVADAS PELOS ALUNOS}

Para esses dois temas, os alunos foram convidados a citar no máximo três mudanças ou três dificuldades que esperavam vivenciar ao ingressar no bacharelado na Haute École ou que vivenciaram desde o ingresso na universidade.

As mudanças observadas no ingresso no bacharelado e no mestrado não são idênticas (Tabela 7). Ao comparar os alunos de bacharelado e mestrado, podemos ver que os alunos de mestrado invocam significativamente mais mudanças, mais qualitativos relacionados ao conhecimento e aos cursos $\left(\chi_{2}(1)=8,801, \mathrm{p}<0,05\right)$. As diferenças qualitativas em termos de tarefas e aprendizagens, bem como de autogestão, são mencionadas com mais frequência pelos alunos do bacharelado. Os alunos de bacharelado são os únicos a evocar mudanças no autodesenvolvimento.

Também surgem diferenças entre os grupos de bacharelado e programas complementares. Assim, os alunos do curso complementar mencionam com mais frequência as mudanças em termos de autodesenvolvimento $\left(\chi_{2}(1)=5,717, \mathrm{p}<0,05\right)$. Estudantes universitários, seja em programas complementares ou de mestrado, têm respostas relativamente semelhantes à pergunta formulada. 


\begin{tabular}{lccc}
\hline $\begin{array}{l}\text { Cite três mudanças importantes que você no- } \\
\text { tou entre o ensino médio e a Haute École. / en- } \\
\text { tre dar aulas no ensino médio e na universidade }\end{array}$ & BA & MA & PC \\
\hline Diferenças qualitativas (conhecimento / curso) & 29,8 & 43,1 & 59,3 \\
\hline Diferenças qualitativas (tarefas e aprendizagem) & 21,3 & 11,8 & 33,3 \\
\hline Diferenças quantitativas (Conhecimento / curso) & 27,7 & 27,5 & 33,3 \\
\hline Diferenças quantitativas (tarefas e aprendizagem) & 2,1 & 9,8 & 1,9 \\
\hline Auto Gerenciamento & 40,4 & 27,5 & 33,3 \\
\hline Auto desenvolvimento & 10,6 & 0 & 33,3 \\
\hline Vida social (relações com outras pessoas) & 21,3 & 17,6 & 33,3 \\
\hline Vida social (relações com professores) & 34,0 & 25,5 & 27,8 \\
\hline Vida social (vida universitária) & 4,3 & 11,8 & 3,7 \\
\hline Outro & 31,9 & 25,5 & 20,4 \\
\hline Sem resposta & 4,3 & 13,7 & 1,9 \\
\hline
\end{tabular}

Tabela 7 - Mudanças observadas por alunos de bacharelado e mestrado (em porcentagem)

Quanto às dificuldades de aprendizagem expressas pelos alunos (Tabela 8), também variam de acordo com o nível de estudo. Constatamos, assim, que as dificuldades qualitativas vinculadas a uma disciplina são mais mencionadas pelos alunos do curso complementar do que pelos alunos do bacharelado $\left(\chi_{2}(1)=11,853\right.$, $\mathrm{p}<0,001)$. O inverso é verdadeiro para as dificuldades relacionadas à organização e autogestão, destacadas pelos alunos de bacharelado $\left(\chi_{2}(1)=7,930, p<0,05\right)$. Restrições organizacionais também são mais evidentes entre os alunos de bacharelado $\left(\chi_{2}(1)=44.271, p<0,001\right)$, porém é importante ressaltar que esse resultado está vinculado principalmente ao contexto de crise sanitária atual.

Alunos de mestrado identificam mais dificuldades qualitativas $\left(\chi_{2}(1)=6,947\right.$, $\mathrm{p}<0,05)$ e quantitativas $\left(\chi_{2}(1)=7,5, \mathrm{p}<0,05\right)$ do que os alunos do bacharelado, mas também mais dificuldades relacionadas à novidade e à necessidade de adaptação $(\chi 2(1)=8,603, p<0,05)$. Em termos de restrições organizacionais, elas são novamente relatadas maciçamente por alunos de bacharelado $\left(\chi^{2}(1)=49,202\right.$, $\mathrm{p}<0,001$ ) pelos mesmos motivos. 
Análise da relação com o saber dos professores em formação inicial - retomada dos...

Por fim, as dificuldades de adaptação ligadas à novidade são mais mencionadas pelos alunos de mestrado do que pelos alunos dos anos complementares.

\begin{tabular}{lccc}
\hline $\begin{array}{l}\text { Encontrou dificuldades de aprendizagem ao } \\
\text { entrar na Haute École / universidade ou des- } \\
\text { de o início do ano? Se sim, por quê? }\end{array}$ & BA & MA & PC \\
\hline Dificuldades qualitativas (disciplinas) & 0 & 13,7 & 22,2 \\
\hline Dificuldades qualitativas (conhecimento / aulas) & 2,1 & 0 & 3,7 \\
\hline $\begin{array}{l}\text { Dificuldades qualitativas (natureza das tarefas e apren- } \\
\text { dizagem) }\end{array}$ & 0 & 3,9 & 3,7 \\
\hline Dificuldades quantitativas & 2,1 & 19,6 & 9,3 \\
\hline Organização, autogestão, confiança & 25,5 & 17,6 & 5,6 \\
\hline Expressão genérica relacionada à mudança, adaptação, & 2,1 & 21,6 & 5,6 \\
novidade & 66,0 & 0 & 3,7 \\
\hline Restriçães organizacionais da universidade & 14,9 & 9,8 & 5,6 \\
\hline Outro & 0 & 0 & 0 \\
\hline Sim, sem explicação & 4,3 & 25,5 & 1,9 \\
\hline Não & 29,8 & 2.0 & 42,6 \\
\hline Não, sem explicação & 0 & 15,7 & 3,7 \\
\hline Sem resposta & & & \\
\hline
\end{tabular}

Tabela 8 - Dificuldades de aprender encontradas por alunos de bacharelado e mestrado (em porcentagem)

\section{Discussão FINAL}

Como um lembrete, nossa pesquisa tem como objetivo identificar as mudanças na relação dos alunos com o conhecimento e a aprendizagem dependendo do estágio de sua formação. Para fazer essa comparação, faremos uma leitura transversal dos principais resultados de nossas análises por registro, a fim de construir um perfil ideal-tipo ${ }^{5}$ de alunos para cada grupo estudado.

5. O ideal-tipo ou tipo ideal podem ser definidos como «uma construção intelectual obtida pela acentuação deliberada de certas características do objeto considerado» (WEBER, [1922] 1988, p. 191; 1965, p. 181 
Os alunos matriculados no primeiro ano de formação de professores têm em média 25,8 anos. Metade deles completou o ensino médio geral e um terço o ensino técnico. Embora alguns deles tenham experimentado a repetência do ensino fundamental, mais da metade desses alunos afirma que reprovou pelo menos uma vez no ensino médio e / ou superior. Depois de alguns meses na Haute École, esses alunos relatam mudanças qualitativas $^{* 6}$, relacionadas às aprendizagens e à autogestão*, bem como dificuldades organizacionais* . Observa-se, entretanto, que esses alunos vinculam essas dificuldades e mudanças às repercussões da atual crise de saúde em seu cotidiano. Em termos de identidade, os alunos matriculados no primeiro ano optaram principalmente por esses estudos porque lhes permitem formar-se para o exercício de uma profissão no setor da educação, ou seja, uma razão essencialmente profissional que corresponde bem aos objetivos da formação que eles estão começando. Do ponto de vista do registro epistêmico, se estes alunos consideram que a aprendizagem lhes permite naturalmente adquirir novos conhecimentos ou desenvolver a sua cultura e curiosidade, a proposição que mais retêm é que aprender é aplicar habilidades e know-how. De forma congruente com essa concepção de aprender, eles definem o conhecimento como um ativo* ou resultado da aprendizagem. Em nossa opinião, essa concepção de aprender e saber poderia sugerir uma relação relativamente instrumental com o conhecimento e a aprendizagem e, de forma mais ampla, com a formação iniciada.

Os alunos do mestrado em educação têm em média 27,67 anos. Se são um pouco mais velhos do que os alunos de bacharelado na formação inicial de professores, geralmente reprovam menos durante a escolaridade e também têm maior probabilidade de obter um diploma de ensino médio geral. Desde a entrada no mestrado, eles notaram significativamente mais mudanças qualitativas* em relação ao conhecimento ensinado e relatam mais dificuldades qualitativas* e quantitativas* do que os alunos do bacharelado. Em termos de identidade, a maioria dos motivos e expectativas que eles relatam diferem significativamente daqueles dos alunos do bacharelado. Assim, se eles esperam de seu curso na universidade um aumento salarial* e veem isso como oportunidade de adiar a entrada no mercado de trabalho*, esses alunos também esperam da carreira universitária um aprofundamento de seus conhecimentos*, novos aprendizados*, um enriquecimento de suas práticas* ou mesmo a descoberta da vida estudantil em contexto universitário*. Em comparação

citado por Coenen-Huther, 2003, p. 532).

6. Os asteriscos denotam a existência de uma diferença significativa entre os grupos. 
Análise da relação com o saber dos professores em formação inicial - retomada dos...

com os alunos do bacharelado, vemos aqui que os motivos dos alunos parecem mais ligados ao desenvolvimento intelectual do que ao desenvolvimento profissional. Quanto ao registro epistêmico, tal como os licenciados, consideram que a aprendizagem lhes permite adquirir novas competências, desenvolver a sua cultura e evoluir intelectualmente. No entanto, eles consideram, significativamente mais do que os alunos do bacharelado, que o conhecimento provavelmente evolui* e que é fruto da construção humana. Quanto aos motivos de ingresso na universidade, as respostas dos alunos de mestrado atestariam, portanto, uma postura mais orientada para o conhecimento em si ou, em todo caso, menos orientada para a aquisição de competências profissionais do que a dos alunos licenciados.

Que lições podem ser aprendidas com essa análise exploratória? Ao ingressar na formação inicial de professores, os alunos tendem a manter uma relação instrumental com o conhecimento e a aprendizagem, enquanto no mestrado os alunos tendem a manter uma relação epistêmica com o conhecimento e sua formação (VERTONGEN et al., 2009). Se esses resultados são geralmente congruentes com os objetivos dos dois cursos de formação em questão, podemos, no entanto, considerar que a formação inicial em docência teria contribuído para deslocar os alunos de uma relação instrumental para uma relação mais livre com o conhecimento e o aprender? À medida que se desenrolou, nossa pesquisa não respondeu a essa pergunta. Na verdade, para avaliar a influência da formação inicial sobre a evolução da relação dos alunos com o conhecimento, idealmente teria sido necessário ter as respostas do mesmo questionário para os alunos ao final do curso de Haute École. Se não tivermos esses dados, poderemos, no entanto, construir o perfil ideal-tipo dos alunos matriculados no programa complementar em ciências da educação. Por precaução, lembramos que as respostas desses alunos vêm de um questionário aberto. Eles, portanto, não têm o mesmo status que os de outros alunos e, além disso, não poderiam ser tratados, estatisticamente, da mesma forma. A comparação que vamos fazer deve, portanto, ser lida com cautela e considerada como uma resposta aproximada à nossa pergunta. Idealmente, teria sido necessário ter as respostas do mesmo questionário para os alunos ao final do curso da Haute École. Se não tivermos esses dados, poderemos, no entanto, construir o perfil ideal-tipo dos alunos matriculados no programa complementar em ciências da educação.

Os alunos do programa complementar têm em média 23,53 anos. Assim como os alunos de mestrado, a grande maioria deles obteve diploma de ensino médio geral e é menos provável que repitam um ano durante a escolaridade. Desde a 
inscrição no programa complementar, esses alunos percebem mudanças qualitativas e quantitativas em relação aos conhecimentos ministrados e aos cursos. Indicam também que neste programa complementar conheceram pessoas que partilham os seus centros de interesse com quem podem discutir (autodesenvolvimento* $\mathrm{e}$ relacionamento com os outros). Tal como os alunos do mestrado em ciências da educação, as dificuldades que relatam são essencialmente qualitativas. Em termos de identidade, as razões para o registro e as expectativas que suscitam se referem ao desejo de aprofundar os seus conhecimentos, continuar a sua formação, desenvolver ou enriquecer as suas práticas e à possibilidade de se reorientarem profissionalmente. Nesse sentido, esses alunos estariam localizados a meio caminho entre os alunos de bacharelado e mestrado. No nível epistêmico, expressam o fato de que a aprendizagem permite adquirir novos conhecimentos e evoluir ao nível intelectual e pessoal. Para eles, o saber é antes de tudo conhecimento, mas também é o resultado do aprender. Observemos que poucos deles evocam espontaneamente o fato de que o saber é uma construção humana ou que tem probabilidade de evoluir. No geral, se o sentido que eles atribuem ao termo « aprender » parece, portanto, bastante próximo daquele dos alunos do bacharelado e do mestrado, aquele que eles atribuem ao « saber » seria mais próximo daquele dos alunos do bacharelado.

Em conclusão, e embora não o possamos afirmar com firmeza, parece que a dimensão identitária dos estudos pode evoluir de uma relação mais instrumental para uma relação mais epistêmica entre os alunos do bacharelado, do curso complementar e do mestrado em ciências da educação. Quanto ao significado atribuído ao termo "saber", seria semelhante para alunos de bacharelado e do programa complementar e diferente para alunos de mestrado em que a dimensão evolutiva aparece de forma significativa. Em outras palavras, a realização do programa complementar em ciências da educação e provavelmente o encontro com professores-pesquisadores ajudaria a influenciar a dimensão epistêmica da relação do aluno com o saber e o aprender.

\section{LIMITES}

Como já mencionamos, a crise sanitária atual (Covid 19) teve repercussões importantes nos métodos de coleta de dados e, por extensão, em sua análise. Em particular, a passagem de um questionário aberto para perguntas fechadas a partir de um conjunto de proposições a partir das quais os alunos eram convidados a fazer uma ou mais escolhas implicou na perda do caráter espontâneo, complexo e 
Análise da relação com o saber dos professores em formação inicial - retomada dos...

singular das respostas dos alunos, caráter, entretanto, considerado como essencial em numerosas pesquisas sobre a relação com o saber.

Cientes desse limite, tivemos o cuidado de preservar a exploração dos três registros da relação com o saber, identificando, para cada um, pelo menos duas questões. Do ponto de vista do tipo de dados coletados e sua análise, a mudança de perguntas abertas para perguntas fechadas também teve o impacto de reunir dados quantitativos em vez de dados qualitativos, que também é típico do trabalho sobre a relação com o saber. Para tirar partido dessa alteração, efetuamos, portanto, análises estatísticas que revelam a existência de tendências diferentes e posições significativamente diferentes entre os grupos de alunos, para cada um dos registros. Por fim, e embora não possamos descartar a existência de efeitos de coorte em nossas análises, todos esses ajustes permitiram reconstruir gradativamente, para as três populações, um quadro global de sua relação com o saber. Fotografia que pode, de certa forma, ser considerada como ideal-tipo para cada população estudada nesta pesquisa e que mereceria, sem dúvida, ser colocada à prova ao mesmo tempo no seio de uma população mais numerosa e com outras ferramentas de coleta de dados.

\section{REFERÊNCIAS}

BAILLET, D. Du rapport au savoir à des rapports aux savoirs: Analyse des difficultés rencontrées par les étudiant.e.s de première année en Psychologie face aux caractéristiques des savoirs universitaires. Tese (Doutorado em Ciências Psicológicas e da Educação) - Faculté des Sciences psychologiques et de l'éducation, Université libre de Bruxelles, Bruxelles, 2017.

BAILLET, D. Le rapport au savoir: une piste pour aborder l'échec et la réussite des étudiant.e.s primo-inscrit.e.s à l'université? Academia, v. 19, 2020. Disponível em: https://mmm.library. upatras.gr/academia/article/viewFile/3264/3518.

BAILLET, D.; REY, B. Rapport au savoir, pratiques d'études et culture disciplinaire à l'université. In: VINCENT, V.; CARNUS, M.-F. (Org.). Le rapport au $(x)$ savoir $(s)$ au cour de l'enseignement: enjeux, richesse et pluralité. Louvain-la-Neuve: De Boeck supérieur, 2015.

BAILLET, D. ; REY, B. Entre variabilité et singularité: analyse des rapports aux savoirs et des difficultés des étudiants en contexte universitaire. In: CARNUS, M. F. ; BUZNIC-BOURGEACQ P.; BAILLET, D. ; THERRIAUL, T. G. ; VINCENT, V. (Org.). Rapport au $(x)$ savoir(s): quels sujets? Quels savoirs? Québec: Livres en ligne du CRIRES, 2020. Disponível em: https://lel.crires.ulaval. $\mathrm{ca} /$ oeuvre/rapports-aux-savoirs-quels-sujets-quels-savoirs.

BAILLET, D.; KAHN, S.; REY, B. Les savoirs enseignés à l'université: une piste pour saisir les difficultés d'apprentissage rencontrées par les étudiants de première année ? Revue française de pédagogie. (accepté).

BAUTIER, E. ; ROCHEX, J-Y. L'expérience scolaire des nouveaux lycéens. Paris: Armand Colin, 1998. 
BEAUCHER, C. La nature du rapport au savoir au regard des aspirations et des projets professionnels d'adolescents de cinquième secondaire. Tese (Doutorado em Ciências da Educação) - Faculté des sciences de l'Éducation, Université du Québec à Montréal, 2004.

BEAUCHER, C.; BEAUCHER, V.; MOREAU, D. Contribution à l'opérationnalisation du rapport au savoir. Esprit critique, v. 17, p. 6-29, 2013.

BERNARD, M. C.; SAVARD, A.; BEAUCHER, C. Le rapport aux savoirs: une clé pour analyser les épistémologies enseignantes et les pratiques de classe. Québec: Livres en ligne du CRIRES, 2014. Disponível em: http://lel.crires.ulaval.ca/public/le_rapport_aux_savoirs.pdf.

CARNUS, M. F.; BAILLET, D.; THERRIAULT, G.; VINCENT, V. Recherches sur le rapport au $(x)$ savoir (s) et formation des enseignants. Un dialogue nécessaire et fructueux. Louvain-la-Neuve: De Boeck Supérieur, 2019.

CHARLOT, B. Du Rapport au Savoir. Éléments pour une théorie. Paris: Anthropos, 1997.

CHARLOT, B. Le rapport au savoir en milieu populaire: une recherche dans les lycées professionnels de banlieue. Paris: Anthropos, 1999.

CHARLOT, B.; BAUTIER, E.; ROCHEX, J-Y. École et savoirs dans les banlieues... et ailleurs. Paris: Armand Colin, 1992.

CHARLOT, B. ; NEVES, E. D. ; SILVA, V. A. Des universités plus hétérogènes. Recherches sur le rapport au savoir des étudiants brésiliens. Academia, v. 10, 2017. Disponível em: http://hepnet. upatras.gr.

DARNON, C.; SMEDING, A.; REDERSDORFF, S. Belief in school meritocracy as an ideological barrier to the promotion of equality. European Journal of Social Psychology, v. 48, n. 4, p. 523-534, 2018.

DUBET, F. Dimensions et figures de l'expérience étudiante dans l'université de masse. Revue française de pédagogie, v. 35, n. 4, p. 511-532, 1994.

DUBET, F. Des raisons d'étudier. Agora débats/jeunesses, v. 6, n. 1, p. 57-68, 1996.

JELLAB, A. Les étudiants en quête d'université. Une expérience scolaire sous tensions. Paris: L'Harmattan, 2011.

LUSSI BORER, V. Les savoirs: un enjeu crucial de l'institutionnalisation des formations à l'enseignement. In: HOFSTETTER, R.; SCHNEUWLY, B. (Org.). Savoirs en (trans)formation. Au cœur des professions de l'enseignement et de la formation. Bruxelles: De Boeck, 2009. p. 41-58. PAIVANDI, S. Apprendre à l'université. Louvain-la-Neuve: De Boeck Supérieur, 2015.

THERRIAULT, G.; BAILLET, D.; CARNUS, M. F.; VINCENT, V. (Org.). Rapport au $(x) \operatorname{savoir}(s)$ de l'enseignant et de l'apprenant. Une énigmatique rencontre. Louvain-la-Neuve: De Boeck Supérieur, 2017.

THERRIAULT, G.; BAILLET, D.; CARNUS, MF.; VINCENT, V. La circulation du rapport au(x) savoir(s) entre l'enseignant et l'apprenant: une piste encore peu explorée. In: THERRIAULT, G.; BAILLET, D.; CARNUS M. F.; VINCENT V. (Org.). Rapport au $(x)$ savoir(s) de l'enseignant et de l'apprenant. Une énigmatique rencontre. Louvain-la-Neuve: De Boeck Supérieur, 2017. p. 7-20.

VERTONGEN, G.; BOURGEOIS, É.; NILS, F.; VIRON, F. D.; TRAVERSA, J. Les motifs d'entrée en formation des adultes en reprise d'études universitaires. L'orientation scolaire et professionnelle, v. 38, n. 1, p. 25-44, 2009. Disponível em: http://osp.revues.org/1829. 
SOBRE A AUTORA

Dorothée Baillet possui mestrado em Ciências da Educação (Université Libre de Bruxelles) e doutorado em Ciências Psicológicas e da Educação (Université Libre de Bruxelles). Ela é pesquisadora do Centro de Pesquisa em Ciências da Educação da Universidade Livre de Bruxelas. Tem experiência na área de pedagogia universitária, com pesquisa nos seguintes temas: a relação dos estudantes com o conhecimento, as dificuldades de aprendizagem dos estudantes e a transição do ensino médio para o superior. Atualmente é pós-doutoranda na Université libre de Bruxelles e na Université du Québec à Rimouski.

ORCID ID: https://orcid.org/oooo-ooo3-116o-1971.

E-mail: dorothee.baillet@ulb.be.

Amélie Adam é professora primária (Haute École Bruxelles-Brabant). Atualmente frequenta o último ano do mestrado em Ciências da Educação (Université Libre de Bruxelles) e é estagiária no Centro de Investigação em Ciências da Educação da Université Libre de Bruxelles.

E-mail: amelie.adam@ulb.be.

Guillaume De Bock é adjunto do primeiro ciclo do ensino secundário, orientador na área de Ciências (AESI, Haute École Bruxelles-Brabant). Frequenta o último ano do mestrado em Ciências da Educação (Université Libre de Bruxelles) e é estagiário no Centro de Investigação em Ciências da Educação da Université Libre de Bruxelles.

E-mail: guillaume.de.bock@ulb.be.

Recebido em 17 de fevereiro de 2021 e aceito em 14 de julho de 2021. 